\title{
Chinese Outbound Shopping Tourism: A Market-Driven Approach for the Luxury and Fashion Industry
}

\author{
Serena Rovai*
}

\begin{abstract}
The relations between tourism and luxury and fashion industry are subject to significant changes because of the quantitative and qualitative discontinuity introduced by the growth of the outbound flows of Chinese tourists and the importance of shopping in their travel experience. The most important implications concern the emergence of a new global market space (the 'Sixth Continent') and of new patterns of integration between the two industries.
\end{abstract}

Keywords: Chinese Outbound Tourism; Shopping Tourism; Luxury Industry; Fashion Industry; Global Markets; Market-Driven Management; Sixth Continent

\section{Shopping Tourism and Luxury}

In recent years both literature and practice of management have been discovering the multifold relations between tourism and shopping, especially as far as luxury and fashion are concerned. Scholars present us with two ideal-types (Timothy, 2005). On the one hand, 'tourism shopping' is the label attached to shopping as a secondary, incidental (although quantitatively relevant) activity during the travel experience. On the other hand, 'shopping tourism' is defined as "a contemporary form of tourism fostered by individuals for whom purchasing goods outside of their usual environment is a determining factor in their decision to travel" (UNWTO, 2014 , p. 13). In particular, shopping determines travel destination in connection with production sites, places (cities) characterized by creativity and design and locations with a convenient variety of shopping opportunities (Rabbiosi, 2011).

Shopping tourism finds its most 'extreme' experience in the setting up of tourist destinations centered on shopping, like in the widely discussed benchmark case of West Edmonton Hall, the 'new generation mall' in Canada (Jansen-Verbeke, 1991), or in the cases of outlet villages, a growing phenomenon in Europe and especially in Italy since the 1990s, where "a retail venue that has become the attraction site for shopping tourism redefines uses, functions and images of the local area in which it is built" (Rabbiosi, 2011).

*Associate Professor, La Rochelle Business School (rovais@esc-larochelle.fr)

Rovai, S. (2016). Chinese Outbound Shopping Tourism: A Market-Driven Approach for the Luxury and Fashion Industry, Symphonya. Emerging Issues in Management (symphonya.unimib.it), 1, 5663. 
As a matter of fact, a much greater variety of intersections between tourism and shopping are taking place in the contemporary economy. One should include also shopping villages (Getz, 1993), cross-border shopping locations (Leal et al., 2010) and all other policy-led developments, in either major or minor locations, that stress the contribution of shopping to tourist flows (Henderson et al., 2011).

No simplified typology seems able to reflect appropriately the multiplicity of combinations of travel motives and environments in which shopping activities end up playing a role (Jansen-Verbeke, 1991). A key variable is time, whose availability allows the realization of leisure in and through shopping: "The longer a visitor tends to loiter in the shopping area, the more the leisure aspect is becoming predominant - the visit then tends to include other activities such as having a drink or a meal, going to the cinema or any other kind of cultural activity. In addition, the longer tourists can be held in a place, the greater the chances that time and money will be spent on shopping" (Jansen-Verbeke, 1991). This explains the important phenomenon of duty-free shopping in airports, whose relevance is (also) linked to the peculiar availability of otherwise idle time of air travellers waiting for their flights.

The intersections between shopping and tourism tend to focus on luxury, expensive, high quality items. This has been explained in terms of consumer behavior, by noticing that shopping behavior during travel differs from ordinary shopping, not only for the disposition to buy 'foolish' items as souvenirs of the travel experience, but also for their search of uniqueness and high quality that contributes to the memorability of the tourist experience as a whole (LeHew \& Wesley, 2007). Although with numerous variations (depending on culture, gender, age, education, social groups), luxury experience is then integrated in the tourist experience (Park et al., 2010).

\section{Tourism and Shopping, the Chinese Way}

The importance of Chinese tourism in the global economy can hardly be underestimated. With double-digit growth in tourism expenditure every year since 2004, China has been since 2012 the world leading source market for outbound tourism: "spending by Chinese travellers increased 25\% in 2015 to reach US\$ 292 billion, as total outbound travellers rose $10 \%$ to 128 million" (UNWTO, 2016).

Quantitative data hide a deeper discontinuity. For the first time in history, travelling abroad becomes an integral part of the lifestyle of large social groups in China: the affluent, first; but now, increasingly, the emerging middle-income class. Thus Chinese tourism is not only a rapidly growing phenomenon, but also a fast changing one. The 'new Chinese tourists' are then defined as "knowledgeable, sophisticated, travel-savvy and predominantly below 45 years of age [...] global yet patriotic', sensitive to communication through social media and other forms of 'WOM squared' (word of mouth and word of mouse) communication", looking for new experiences and places, willing to 'purchase more goods for themselves and fewer for their friends and relatives back home, as their peers are more likely to travel internationally as well' (Arlt, 2011).

Change concerns also the new trends in consumer behavior in the luxury sector. For many Chinese, luxury purchasing is no longer only associated with the pleasure 
of buying a beautiful and expensive item (often to 'show off'), but it has an experiential dimension, becoming a part of a new lifestyle, improving the quality of life. This means a new focus on spending in sectors such as travel, wellness, house appliances and culture in addition to the fashion and other classical luxury sectors, with a delayed convergence with the global trend towards 'experiential luxury' (Rovai, 2014; Abtan et al., 2014). After decades of uniformism and extremely regulated consumption habits, China's love for luxury cannot be just interpreted as the result of a convergence towards westernized, global patterns of consumption, but reflects a deeper re-appropriation of elements that are key in Chinese culture and are nurtured by a centuries-long history of luxury (Rovai, 2016).

This helps to explain the very complex scenario of Chinese luxury markets nowadays. On the one hand, at the same time as Chinese consumers show greater brand awareness and an increasing role of buying motivations linked to quality, uniqueness, authenticity and high levels of craftsmanship, both Western multinational corporations and the emerging Chinese brands are facing the competitive challenge of introducing 'Chineseness' in their products' design. On the other hand, this happens in a domestic market whose growth is restrained by a multiplicity of factors from luxury imports regulations affecting luxury garments prices to government 'moral conduct' rules and codes restricting consumption behavior in particular related to corporate gifts (Rovai, 2016).

As a consequence, the demand for luxury increasingly finds an opportunity for satisfaction during outbound travel experiences. Western media often like to present the caricature of Chinese tourists as shopping maniacs, moving noisily in groups in search of expensive bags. With a mix of hypocrisy and ignorance, they are depicted with undisguised contempt for their apparent disregard of the highest expressions of our culture and history.

Behind the caricature, travel motivations of Chinese tourists are significantly status-related and shopping is perceived as a relevant part of the tourists' experience abroad. Different sources confirm that Chinese tourists tend to be quite price-conscious on items such as the flight ticket or overnight stays, and tend to allocate a greater share (approximately 30 - 35\%) of their budget to shopping (Uren, 2009; UNWTO, 2014).

\section{The Luxury and Fashion Industry and Chinese Tourism}

The market-driven approach has been an increasingly relevant character of the luxury and fashion industry in recent times. In fact the 'luxury' concept itself has changed over time as a result of the fast growing accessibility to luxury products and new modes of purchasing in the recent years (Kapferer, 2012). Luxury goods and services are characterized by the nature of high price and rarity (Dubois \& Laurent, 1994), but luxury may have different and variable forms for many different people according to the mood and experience of the customers (Wiedmann et al., 2009).

Therefore strengthening relations with the customers, based on their identification with the brand values, is key to strategies in the fashion and luxury industry and requires both a careful management of information flows from the market and structured (and faster) product development processes (Mosca, 2008; Sola et al., 
2015). In China, the emergence of younger segments of luxury consumers (under 40 years old) has led an increasing number of luxury brands to market digitalization, that is a far from obvious choice for exclusivity-oriented businesses (in contrast, e.g., with fast-fashion producers: cf. Arrigo, 2010). However in recent years digital communication and shopping, often involving a diversified pool of luxury sectors, has been crucial in increasing brand awareness and is becoming the cornerstone of the companies' new information systems in order to understand and interpret the new generations of Chinese customers (Rovai, 2016, Chapter 7).

\subsection{The Sixth Continent}

A very important implication of the market-driven approach of luxury companies is the emergence of a new market space that in the industry jargon is often referred to as 'the Sixth Continent' (The Economist, 2014). This expression has been originally related to airports' duty free shopping areas. Their importance is linked to their nature of captive marketplaces for the huge numbers of air travellers during their forced idle time waiting for departure or, at international hubs, during sometimes hours-long transfers. However, to luxury and fashion companies' airport duty free areas are also a precious 'learning market' space. "Airports are also laboratories", a "kind of control tower", where companies can spot information, trace customers' flows and elaborate indicators on customer behavior, identify specific adjustments to be implemented in certain key foreign markets, anticipate 'market bubbles' and test their competitive positioning before engaging in opening stores abroad (The Economist, 2014).

The Sixth Continent idea, however, may be easily extended to all travel-related shopping areas and include malls, designer outlets and urban fashion districts and then describe a new space, that spans around the globe and highlights a geographically discontinuous network of shopping locations. This market space is global and cosmopolitan, but at the same time it allows to develop cultural-specific ways to addressing luxury shoppers.

Dealing with the Chinese shoppers is the most visible priority in most of these Sixth Continent locations. In this respect the key action consists of a number of adaptations in distribution and in its service component. These adaptations have a double aim. On the one hand, there is the need to facilitate the buying process: "tourists are likely to perceive shopping risks. Hence, tourists tend to purchase expensive products from a renowned venue or destination to reduce anxiety and enhance their confidence" (Choi et al., 2016). On the other hand, service quality is instrumental to a memorable and 'authentic' in-store shopping experience.

In practice, Western luxury brands started to integrate dedicated and personalized services in flagship and duty free stores. This is realized by providing systematic Chinese language support (signs, flyers etc.), personal shopping assistance with guided visits in Mandarin language, backstage access to fashion shows in special occasions and exclusive visits to sites of interest related to the brand, such as their craftsmanship laboratories in order to show the unique high quality manufacturing heritage and know-how. Chinese retailing personnel will be able to understand the Chinese customer's requirements associated to service standards, cultural norms, merchandising preferences and negotiating tactics. 
Furthermore, during Chinese festivities, luxury flagship stores offer a purchasing experience with a 'Chinese touch', honoring (e.g. with dedicated shop windows) the Chinese cultural rituals and symbols during that specific festivity. 'Chineseness' is duly emphasized, especially by those brands, like Gucci or Louis Vuitton, which have specifically designed and created bags inspired from the annual Chinese New Year astrological symbol.

Digital strategies are also involved in this effort. Due to the remarkable diffusion of social networks in China, Chinese tourists, before leaving for their overseas shopping destinations, are very likely to access to social media platforms, such as WeChat, and to get shared information in Chinese language about luxury goods and shopping experiences abroad, as well as to compare prices and products availability. Those experiences and advices will be a very significant influencer of future shoppers. Consequently, customer satisfaction is also important in order to capitalize on the positive experience for future Chinese visitors.

\subsection{The Integration with the Tourism Industry}

A second set of implications concern the increasing integration of luxury and fashion companies with the tourist industry.

An obvious example is the cooperation with established actors in the tourism industry. These actors include especially hotels, airlines, and companies managing airports and cruise terminals. Luxury and fashion products and activities are thus incorporated into the tourist packages. Luxury hotels utilize branded luxury products in their own services and host exclusive shopping malls or are located in a position with direct access to luxury shopping areas. International airports set up exclusive (and paid) 'personal shopper' services, with qualified 'image consultants' guiding the 'discerning traveller's to help them select their purchases.

Cooperation also takes place with tour operators and hotel chains, in order to provide additional experiences ranging from guided shopping tours to pass ticket reservation for fashion shows.

All the above can be further specified with attention to Chinese tourists, especially as major hotel chains develop ad hoc programs involving staff cultural training and China-focused services as Chinese food choices, Mandarin speaking staff, China festivities hotel adornments with colors and symbols of Chinese culture and traditions. In some cases, hotels fully specialize to appeal to that particular clientele and their 'servicescape' is designed specifically for the Chinese customers (like in the case of the Hualuxe brand by Intercontinental). Chinese personalized programs involve Chinese-oriented luxury and fashion goods. E.g., Hilton partnered with iconic international fashion designer Vivienne Tam to produce limited-edition 'Water Dragon' slippers as part of an exclusive program offering tailored welcome experiences for Chinese travellers at 70 participating hotels in 23 countries.

Destination managers are also increasingly concerned with the potential of shopping as part of the local tourist experience and make luxury shopping the object of specific promotional campaigns. E.g. in 2014 London Luxury Quarter, VisitBritain and British Airways co-hosted an event ('London Luxury. By Appointment') to contact wealthy individuals in Shanghai and Chengdu and 
connect them 'before travel' with brands such as Fortnum \& Mason and Selfridges already in their own country.

This is by no means an obvious choice. Even in Paris leisure shopping has only been recently selected as a destination strategy, despite the city's reputation (Rabbiosi, 2014). A study of the case of Tuscany (Italy) shows a gap between the Chinese perception of fashion as a distinctive element of the Italian culture and the Italian tendency to clearly dissociate shopping from 'high culture' (Bellini, Baratta, Loffredo, \& Rovai, 2014).

The 'culturalization' of luxury shopping, pulled by the demands and the sensitivity of the new tourists (like the Chinese), is producing one more fundamental evolution in the strategy of luxury and fashion companies, as they start to reinterpret their role in the urban contexts and become actors of the local tourist industry. This is partially in continuity with the emphasis on the symbolic value of flagship stores, as emotional repository and showpieces of the brand's heritage (Arrigo, 2011; Manlow \& Nobbs, 2013). Another important phenomenon is the sponsorship of major restorations (like in the case of the Colosseum in Rome by Tod's), although there is no empirical evidence of its actual impact on Chinese visitors.

Companies increasingly realize that they are part of a dense network of associations with products, organizations, people, sites, artifacts and institutions that is reflected into a unique (urban) 'brandscape'. In the benchmark case of Florence, luxury and fashion companies have increasingly performed a 'destination strategy', including:

1. the insertion of fashion brands in the city's heritage, e.g. when Florentine cultural institutions host fashion events;

2. the insertion of artworks in fashion brand venues, like the flagship stores;

3. the development of new cultural institutions of the city of art through the 'musealisation' of the company's heritage concerning luxury and style (Bellini \& Pasquinelli, 2016).

Chinese tourists have been a specific target of these actions, linking the 'high culture' and shopping experiences through the sophisticated mediation of the 'luxury museum': e.g. they are offered exclusive personalized packages that include the museum visit as a way to strengthen their loyalty and brand awareness. This may happen in different ways. Looking at Florence, in its benchmark event of 2012, the Ferragamo Museum played the role of connecting fashion design and high culture by stressing the cross-references between Marilyn Monroe's modern icon and art history. The exhibition provided the visitors with a fascinating narrative involving the work of the famous shoemaker and led them, after exiting the exhibition, straight into the flagship store. With a different approach, the Gucci Museum becomes also a shop, 'The Icon Store', hosting unique editions of bags, scarfs etc. that are available only at the museum.

\section{Conclusions and Emerging Issues}

The 'market-driven management' literature has emphasized the importance of managing information flows and of the companies' outside-in capabilities (Brondoni, 2009). For the fashion and luxury industry, the accelerating process of 
convergence with tourism provides not only new market spaces (the 'sixth continent'), but also new opportunities to interact with (and learn from) the market, whose strategic, operational and conceptual implications have only been partially explored.

An important emerging issue concerns the ways in which this convergence is taking place. E.g. let us consider the phenomenon of luxury hospitality by hotels as extension of the fashion brands: will that integration lead fashion and luxury companies to a more direct engagement in tourism or be limited to a web of joint ventures and strategic alliances?

A second issue may concern the relationship of luxury and fashion brands with some of tourism's key dimensions such as culture, heritage, and authenticity, which may not be necessarily in tune with the globalized and intercultural approaches to product development followed by multinational corporations.

\section{Bibliography}

Abtan, O. et al. (2014). Shock of the New Chic: Dealing with the New Complexity in the Business of Luxury. Boston, MA: The Boston Consulting Group.

Arlt, W. (2011). Make hay from the second wave, China Daily (European edition), Dec. 2, 2011. Retrieved from: http://www.chinatraveltrends.com

Arrigo, E. (2010). Innovation and Market-Driven Management in Fast Fashion Companies. Symphonya. Emerging Issues in Management, 2, 67-85.

http://dx.doi.org/10.4468/2010.2.06arrigo

Arrigo, E. (2011), Fashion, Luxury and Design: Store Brand Management and Global Cities Identity. Symphonya. Emerging Issues in Management, 1, 55-67.

http://dx.doi.org/10.4468/2011.1.06arrigo

Bellini, N., Baratta, V., Loffredo, A., Rovai, S. (2014). Chinese tourists in Tuscany: Redefining the relationship between heritage and authenticity. In: Proceedings of the Heritage, Tourism and Hospitality International Conference HTHIC 2014 (pp. 104-115). Istanbul: Boğaziçi University.

Bellini, N., Pasquinelli, C. (2016). Urban brandscape as value ecosystem: The cultural destination strategy of fashion brands. Place Branding and Public Diplomacy, 12, 5-16.

http://dx.doi.org/10.1057/pb.2015.21

Brondoni S. (2009), Market-Driven Management, Competitive Customer Value and Global Networks. Symphonya. Emerging Issues in Management, 1, 8-25.

http://dx.doi.org/10.4468/2009.1.02brondoni

Choi, M., Law, R., Heo, C.Y. (2016). Shopping destinations and trust - Tourist attitudes: Scale development and validation. Tourism Management, 54, 490-501.

http://dx.doi.org/10.1016/j.tourman.2016.01.005

Dubois, B., Laurent, G. (1994). Attitudes towards the concept of luxury: An exploratory analysis. in J. A. Cote \& Siew Meng Leong (Ed.s), AP-Asia Pacific Advances in Consumer Research, Volume 1 (pp. 273-278). Provo, UT : Association for Consumer Research.

Economist, The (2014). The sixth continent. May 10. Retrieved from: http://www.economist.com/node/21601885

Getz, D. (1993). Tourist shopping villages. Development and planning strategies. Tourism Management, February, 15-26.

Henderson, J., Chee, L., Mun, C.N., Lee, C. (2011). Shopping, tourism and retailing in Singapore. Managing Leisure, 16, 36-48.

http://dx.doi.org/10.1080/13606719.2011.532599 
Jansen-Verbeke, M. (1991). Leisure shopping. A magic concept for the tourism industry?. Tourism Management, March, 9-14.

Kapferer, J. (2012). The Luxury Strategy: Break the Rules of Marketing to Build Luxury Brands. London: Kogan Page Ltd.

Leal, A., López-Laborda, J., Rodrigo, F. (2010). Cross-Border Shopping: A Survey. International Advances in Economic Research, 16, 135-148.

http://dx.doi.org/10.1007/s11294-010-9258-z

LeHew, M., Wesley, S. (2007). Tourist shoppers' satisfaction with regional shopping mall experiences. International Journal of Culture, Tourism and Hospitality Research, 1(1), 82-97.

http://dx.doi.org/10.1108/17506180710729628

Manlow, V., Nobbs, K. (2013). Form and function of luxury flagships. Journal of Fashion Marketing and Management: An International Journal, 17 (1), 49 - 64.

http://dx.doi.org/10.1108/13612021311305137b

Mosca, F. (2008), Market-Driven Management in Fashion and Luxury Industries, Symphonya. Emerging Issues in Management, 1, 65-71. doi: 10.4468/2008.1.06mosca

Park, K., Reisinger, Y., Noh, E.-H. (2010). Luxury Shopping in Tourism. International Journal of Tourism Research, 12, 164-178.

http://dx.doi.org/10.1002/jtr.744

Rabbiosi, C. (2011). The invention of shopping tourism. The discursive repositioning of landscape in an Italian retail-led case. Journal of Tourism and Cultural Change, 9 (2), 70-86.

http://dx.doi.org/10.1080/14766825.2010.549233

Rabbiosi, C. (2014). Renewing a historical legacy: Tourism, leisure shopping and urban branding in Paris. Cities, 42(Part B), 195-203. http://dx.doi.org/10.1016/j.cities.2014.07.001

Rovai, S. (2014). The Evolution of Luxury Consumption in China. In Atwal, G., Bryson, D. (Ed.s), Luxury Brands in Emerging Markets (pp. 130-134). London: Palgrave Macmillan.

Rovai, S. (2016). Luxury the Chinese Way. New Competitive Scenarios. London: Palgrave Macmillan.

Sola D., Scarso Borioli G., Scalabrini G. (2015). New Product Development and Disciplined Experimentation. Symphonya. Emerging Issues in Management, 2, $105-119$.

http://dx.doi.org/10.4468/2015.2.08sola.scarsoborioli.scalabrini

Timothy, D. J. (2005). Shopping tourism, retailing and leisure. Clevedon: Channel View.

UNWTO (2014). Global Report on Shopping Tourism. Madrid.

UNWTO (2016). World Tourism Barometer, vol. 14 (May). Madrid.

Uren, J. (2009). The Chinese outbound travel market, Tourism Insight. Retrieved from: www.insights.org.uk

Wiedmann, K.P., Hennigs, N., Siebels, A. (2009). Value-based segmentation of luxury consumption behavior. Psychology \& Marketing, 26(7), 625-651.

http://dx.doi.org/10.1002/mar.20292 